\title{
Indoor Air Quality Improvement and Purification by Atmospheric Pressure Non-Thermal Plasma (NTP)
}

\section{Prince Junior Asilevi}

Kwame Nkrumah University of Science and Technology

Patrick Boakye ( $\sim$ patrickboakye@knust.edu.gh )

Kwame Nkrumah University of Science and Technology

\section{Sampson Oduro-Kwarteng}

Kwame Nkrumah University of Science and Technology

\section{Bernard Fei-Baffoe}

Kwame Nkrumah University of Science and Technology

Yen Adams Sokama-Neuyam

Kwame Nkrumah University of Science and Technology

\section{Research Article}

Keywords: non-thermal plasma, dielectric barrier discharge, indoor air quality, formaldehyde

Posted Date: August 4th, 2021

DOI: https://doi.org/10.21203/rs.3.rs-763141/v1

License: (c) (1) This work is licensed under a Creative Commons Attribution 4.0 International License.

Read Full License

Version of Record: A version of this preprint was published at Scientific Reports on November 24th, 2021. See the published version at https://doi.org/10.1038/s41598-021-02276-1. 


\title{
Indoor air quality improvement and purification by atmospheric pressure Non-Thermal Plasma (NTP)
}

Prince Junior Asilevi ${ }^{1}$, Patrick Boakye ${ }^{2,}$, Sampson Oduro-Kwarteng ${ }^{1}$, Bernard Fei-Baffoe ${ }^{3}$, and Yen Adams Sokama-Neuyam ${ }^{4}$

${ }^{1}$ Department of Civil Engineering, Kwame Nkrumah University of Science and Technology, Kumasi, Ghana

${ }^{2}$ Department of Chemical Engineering, Kwame Nkrumah University of Science and Technology, Kumasi, Ghana

${ }^{3}$ Department of Environmental Science, Kwame Nkrumah University of Science and Technology, Kumasi, Ghana

${ }^{4}$ Department of Petroleum Engineering, Kwame Nkrumah University of Science and Technology, Kumasi, Ghana

* Corresponding email: patrickboakye@knust.edu.gh

\begin{abstract}
Non-thermal plasma (NTP) is a promising technology for the improvement of indoor air quality (IAQ) by removing volatile organic compounds (VOCs) through advanced oxidation process (AOP). In this paper, authors developed a laboratory scale dielectric barrier discharge (DBD) reactor which generates atmospheric NTP to study the removal of low-concentration formaldehyde (HCHO), a typical indoor air VOC in the built environment associated with cancer and leukemia, under different processing conditions. Strong ionization NTP was generated between the DBD electrodes by a pulse power zero-voltage switching flyback transformer (ZVSFBT), which caused ionization of air molecules leading to active species formation to convert HCHO into carbon dioxide $\left(\mathrm{CO}_{2}\right)$ and water vapor $\left(\mathrm{H}_{2} \mathrm{O}\right)$. The impact of key electrical and physical processing parameters i.e. discharge power $(\mathrm{P})$, initial concentration $\left(\mathrm{C}_{\mathrm{in}}\right)$, flow rate $(\mathrm{F})$, and relative humidity $(\mathrm{RH})$ which affect the formaldehyde removal efficiency ( $\mathrm{n}$ ) were studied to determine optimum conditions. Results show that, the correlation coefficient $\left(\mathrm{R}^{2}\right)$ of removal efficiency dependence on the processing parameters follow the order $R^{2}(F)=0.99>R^{2}(R H)=$ $0.96,>\mathrm{R}^{2}\left(\mathrm{C}_{\mathrm{in}}\right)=0.94>\mathrm{R}^{2}(\mathrm{P})=0.93$. The removal efficiency reached $98.45 \%$ under the optimum conditions of $\mathrm{P}=0.6 \mathrm{~W}, \mathrm{C}_{\mathrm{in}}=0.1 \mathrm{ppm}, \mathrm{F}=0.2 \mathrm{~m}^{3} / \mathrm{h}$, and $\mathrm{RH}=65 \%$ with no secondary pollution. The study provided a theoretical and experimental basis for the application of DBD plasma for air purification in the built environment.
\end{abstract}


Keywords: non-thermal plasma, dielectric barrier discharge, indoor air quality, formaldehyde

\section{Introduction}

Indoor air quality (IAQ) is a critical factor for environmental health safety in the built environment, which often has substandard conditions due to emissions of volatile organic compounds (VOCs) [1]. Formaldehyde (HCHO) is among the common indoor air VOC pollutants directly harmful to the eyes and respiratory system, as well as the central nervous system, which could cause symptoms such as headache, dizziness, tearing, and nausea. Even worse, extensive peer review has associated the organic pollutant to various cancers and leukemia, requiring that $\mathrm{HCHO}$ concentration in the indoor air space be strictly regulated at 0.1 ppm according to the World Health Organization $[2,3]$.

Conventionally, IAQ is improved mainly by emission source control, ventilation, and air purification [4]. Emission control and ventilation in many cases are practically inaccessible owing to the ubiquitous nature of most indoor air VOCs and since buildings have become more airtight to improve air-conditioning and heating efficiency [5]. Meanwhile, air purification has become the most promising method to improve IAQ. However, many air purification techniques such as catalytic combustion, adsorption, membrane separation, biodegradation, and photocatalysis have the disadvantages of low efficiency, secondary pollution, high technical requirements, high maintenance cost, short service life and small application range. What's more, the emergence of strict regulations on VOC emission levels poses the mandate to consider precision, high efficiency, and high accuracy in the decomposition of formaldehyde. In this pursuit, reactor efficiency, mechanism, and relevant degradation reactions are key treatment parameters [6].

Meanwhile in recent years, research on the application of atmospheric Non-thermal plasma (NTP) generated at ambient conditions for indoor air purification has heightened mainly due to the advantage of high VOC removal efficiency, high energy efficiency, and no secondary pollution. The purification occurs mainly by mixing the VOC contaminated air with a high

ionization NTP containing energetic electrons and active particles which proceed to numerous 
inelastic collisions with the VOC molecules leading to degradation and subsequent conversion to $\mathrm{CO}_{2}$ and $\mathrm{H}_{2} \mathrm{O}$. The NPT generation involves the oxidation and ionization of air molecules $\left(\mathrm{O}_{2}\right.$, $\mathrm{N}_{2}$, and $\mathrm{H}_{2} \mathrm{O}$ ) by high voltage induced energetic electrons to form reacting radicals such are $\mathrm{OH}$, $\mathrm{HO}_{2}, \mathrm{O}, \mathrm{N}$, and $\mathrm{H}$ along with other active particles such as $\mathrm{O}_{3}$, and $\mathrm{H}_{2} \mathrm{O}_{2}$ energetic enough to attack organic molecules. However, some challenges associated with this emerging technology include low mineralization efficiency, generation of some undesirable byproducts such as ozone $\left(\mathrm{O}_{3}\right)$, and in a few NPT types low energy efficiency $[7,8]$.

Dielectric barrier discharge (DBD) is a good source of atmospheric NTP with low-cost plasma for indoor air VOC pollution control. DBD has the reputation to efficiently remove low concentrations of VOCs and odorous compounds plus the added advantage of energy saving and no production of dioxin [9]. Many researchers have studied NTP application for the improvement of IAQ. Timmermann [10] developed a type of DBD plasma for hospital theatre indoor air purification, especially designed to generate ionic wind to filter out airborne microorganisms. The results of $90 \%$ air purification by removal of airborne Escherichia coli was shown, and not necessarily VOC removal. Zadi [11] reported the synergistic effect of NTP with photo-catalysis process for indoor air treatment in refrigerated food chambers by removing propionic acid and benzene as target VOCs. Even though a high removal efficiency was achieved, energy efficiency and operation cost is a major set-back. Yuan [12] efficiently removed formaldehyde by a combined $\mathrm{MnO}_{2}$ catalyst assisted NTP with physical adsorption. However, catalyst application in NTP indoor air treatment have shown poisoning effect and secondary pollution $[9,13]$. In a previous study, Asilevi [9] showed over 95\% HCHO degradation by an atmospheric strong ionization DBD system applicable to industry waste air with concentration range of 100-400 ppm, hence not relevant for low-concentration formaldehyde removal typical to the built environment.

The aim of this study therefore, was to develop and test an enhanced dielectric electric barrier discharge plasma system for indoor air purification, by the degradation of low concentration formaldehyde (HCHO). A high voltage driver was used to enhance the DBD ionization characterized by a strong electric field strength, greater average electron energy, and high electron density. The key task was to establish an optimum protocol by the effect of electrical and physical processing parameters viz., discharge energy, initial HCHO concentration, relative humidity (RH), and flow rate, and to analyze the degradation reactions. In addition, a brief 
operation cost analysis is presented. The study is relevant for the commercial manufacturing of DBD plasma as a promising indoor air purification technology.

\section{Materials and methods}

\subsection{Fabrication of the DBD reactor and experimental setup}

A schematic representation of the indoor air purification experimental setup to study the decomposition of low concentration $\mathrm{HCHO}$ is shown in figure 1. There are three operational components: (1) the gas flow component comprising of dry air cylinder supplying dry air through bubbler towers under flow control to regulate the air- water vapor-formaldehyde mix, (2) the reactor component comprising of the enhanced ionization dielectric barrier discharge (DBD) reactor, high voltage driver, and (3) the analysis component comprising of the smart sensor humidity meter, gas chromatography, and aeroqual series $500 \mathrm{HCHO}$ detector. The experimental conditions are summarized in Table 1.

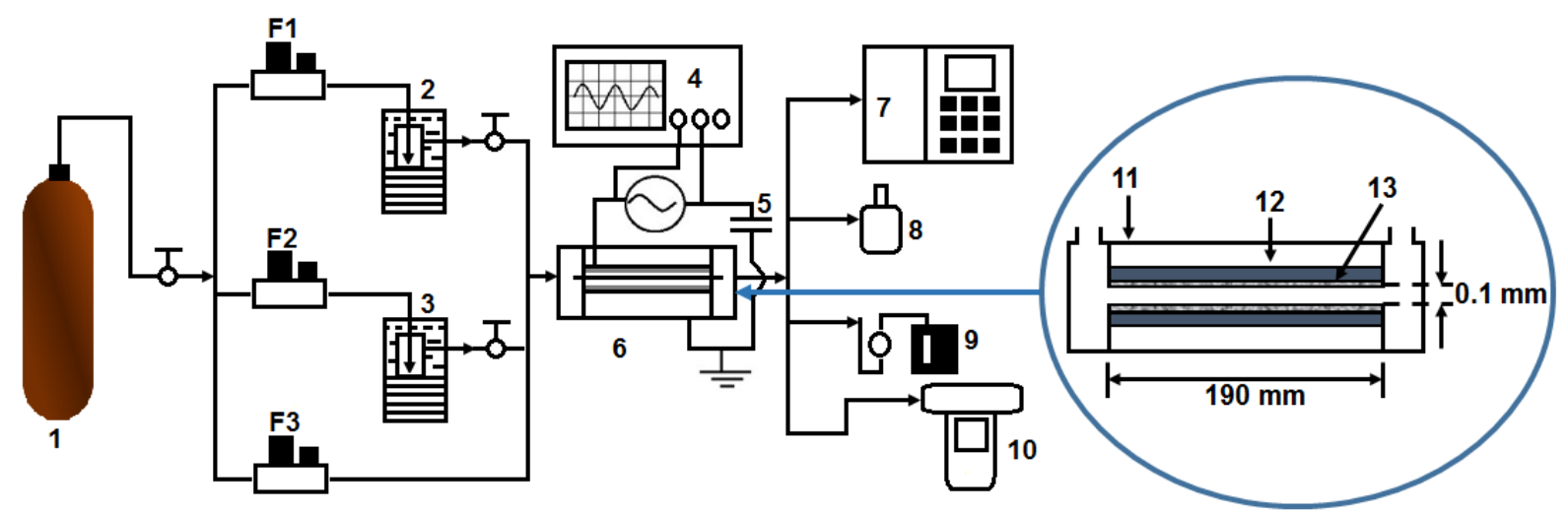

Figure 1: Schematic of the experimental setup. 1- dry air cylinder; 2- water-containing bubble tower, 3- HCHO-containing bubble tower, 4- oscilloscope, 5- monitor capacitor, 6- DBD reactor, 7- GC, 8- smart sensor humidity meter, 9- gas sampler, 10- aeroqual series 500, 11PVC tube housing, 12- Steal plate electrode, and 13- aluminum oxide dielectric material. F1, $\mathrm{F} 2$, and $\mathrm{F} 3$ are the flow rate meters

The main experimental device is the DBD reactor which generates active species by an enhanced ionization discharge system. The fabricated chamber and schematic of DBD reactor is illustrated in figure 1. The plasma electrodes are made from two rectangular stainless steel plates 
each $100 \mathrm{~mm}$ x $190 \mathrm{~mm}$, facing each other at $0.1 \mathrm{~mm}$ distance using an insulating tapes, and covered by a $300 \mu \mathrm{m}$ thick super dielectric material (SDM) made from high surface area aluminum oxide powder with dielectric constant $\varepsilon r \sim 10^{4}$. With the special characteristics of small discharge gap $\left(1_{\mathrm{g}}\right)$ and high dielectric constant $\left(\varepsilon_{\mathrm{d}}\right)$, a high electric field intensity $\left(10^{7} \sim 10^{8}\right.$ $\mathrm{V} / \mathrm{m}$ ) producing strong ionization under atmospheric pressure could be obtained according to equation 1(Zhang et al., 2013; Fromille and Phillips, 2014).

$$
\mathrm{E}_{\mathrm{g}}=\frac{\mathrm{V} \varepsilon_{\mathrm{d}}}{2 \mathrm{l}_{\mathrm{d}} \varepsilon_{\mathrm{g}}+\mathrm{l}_{\mathrm{g}} \varepsilon_{\mathrm{d}}^{\prime}}
$$

Here, $\mathrm{E}_{\mathrm{g}}(\mathrm{kV} / \mathrm{cm}), 1_{\mathrm{d}} / \mathrm{l}_{\mathrm{g}}(\mathrm{cm})$, and $\varepsilon$ are the electric field intensity, plate length, clearance, and permittivity respectively. Using a high voltage driver power supply capable of producing high voltage/high frequency of $2.5-7.2 \mathrm{kV} / 30 \sim 50 \mathrm{kHz}$ between the discharge electrode and the ground electrode, the $\mathrm{O}_{2}$ and water vapor molecules present in the air stream are strongly ionized to form active species such as $\bullet \mathrm{O}, \mathrm{O}_{3}$, and $\bullet \mathrm{OH}$. Finally, the enhanced ionization DBD reactor is housed in a cylindrical PVC tube and sealed by adhesive to ensure no air leakage.

It is important to consider that, the dielectric material and its processing technology are the key to achieve a stable and enhanced electrical ionization discharge in the DBD plasma. Other researchers used dielectric materials made from glass, quartz, ceramics, polymers and other materials of relatively low dielectric and high breakdown strength (Tao et al., 2011). This paper followed the dielectric material processing technology described by Fromille and Phillips (2014). Furthermore, in this type of DBD plasma design, almost all the electron energy (equation 2) acquired from the applied electric field was transferred to the air molecules.

$$
\mathrm{T}_{\mathrm{e}}=\frac{\sigma \mathrm{m}_{\mathrm{h}} \mathrm{E}_{\mathrm{g}}^{2}}{3 \mathrm{kn}_{\mathrm{e}} \mathrm{m}_{\mathrm{e}} \mathrm{v}_{\mathrm{e}}^{\prime}}
$$

where, $\mathrm{n}_{\mathrm{e}}\left(\mathrm{cm}^{-3}\right)$ represents electron concentration, and $\mathrm{m}_{\mathrm{e}}(\mathrm{eV})$ and $\mathrm{m}_{\mathrm{h}}(\mathrm{eV})$ are the mass of electron and heavy particles respectively, $\mathrm{k}, \mathrm{v}_{\mathrm{e}}\left(\mathrm{sec}^{-1}\right), \sigma(\mu \mathrm{S} / \mathrm{cm}), \mathrm{E}_{\mathrm{g}}(\mathrm{kV} / \mathrm{cm})$ stand for the Boltzmann constant, electron collision frequency, plasma conductivity, and discharge intensity of the electric field, respectively.

In order to achieve a stable and strong ionization in the non-thermal plasma generated between the DBD electrodes, a zero-voltage switching (ZVS, XH-M652, 30 50 kHz) flyback transformer (FBT) with MOSFET switches and high pulsed-power output improvised from a 
CRT television was used (figure 2a). The FBT was driven by an electronic control compact fluorescent tube (CFT) ballast circuit, which is cheap and readily available, at $12 \mathrm{~V}$ AC input voltage (figure $2 \mathrm{a}$ ) to generate a continuous electrical discharge. Figure $2 \mathrm{~b}$ shows an equivalent circuit of the FBT; during switch on mode the diode D is reverse-biased when transistor Q conducts, and the primary winding then functions as an inductor, connected to the input source $\mathrm{V}_{\mathrm{g}}$. With an input voltage of $12 \mathrm{~V} \mathrm{AC}$, the FBT is expected to generate about $7.2 \mathrm{kV}$ which is 600 times the input voltage (Salem et al., 2006).

(a)
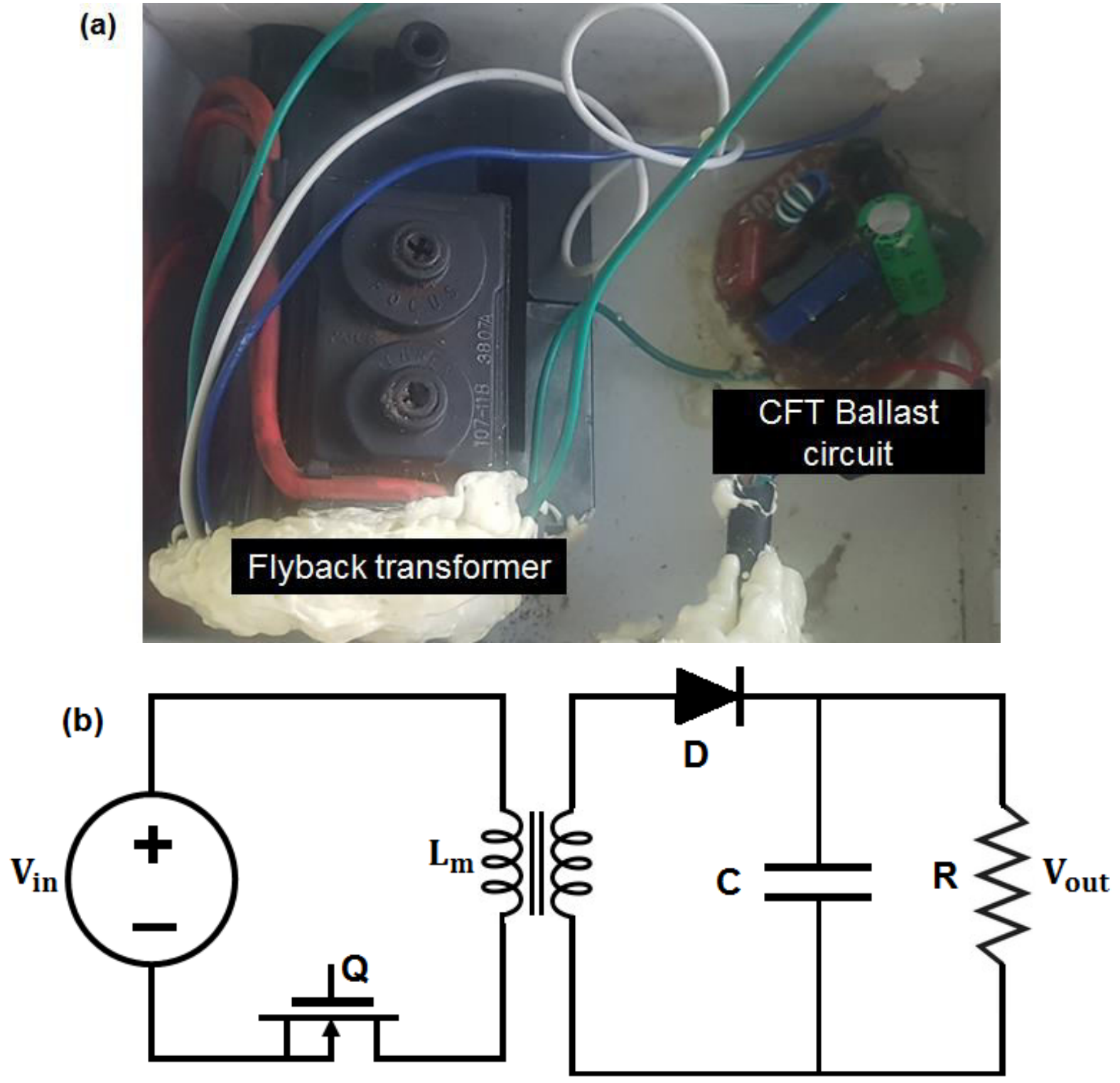

Figure 2: (a) Strong ionization voltage supply shoeing flyback transformer and CFT ballast circuit and (b) equivalent circuit of FBT adapted from Salem et al. (2006). 
During the non-thermal plasma discharge process, the discharge energy flow density can reach $2.1 \mathrm{~W} / \mathrm{cm}^{2}$, and the average electron energy can exceed $10 \mathrm{eV}$. Thus, the system can be categorized as a strong electrically active ionization discharge, with far higher energy intensity characteristics compared to similar DBD designs, in which the dielectric barrier micro-discharge is only a local glow and the discharge intensity is weak and uniform under atmospheric pressure [14]. In this paper, the plasma discharge characteristics of the DBD reactor generates appreciably stable discharge. Moreover, the ionization intensity is comparably far higher than other atmospheric pressure discharges [15]. Table 1 summarizes the electrical characteristics of the DBD devise designed in this paper, based on the special materials used.

Table 1: Experimental measurement conditions and electrical characteristics of DBD reactor

\begin{tabular}{ll}
\hline Parameter & Value \\
\hline Reactor volume & $1.9 \mathrm{~cm}^{3}$ \\
Initial $\quad$ HCHO & $0.1-10 \mathrm{ppm}$ \\
concentration & \\
Relative humidity (RH) & $20-90 \%$ \\
Gas pressure & $\geq 0.1 \mathrm{MPa}$ \\
Electric field intensity & $10^{7} \sim 10^{8} \mathrm{~V} / \mathrm{m}$ \\
Electron concentration & $>10^{13} \mathrm{~m}^{-3}$ \\
Electron average energy & $>10 \mathrm{eV}$ \\
Discharge power & $1-5 \mathrm{~W} / \mathrm{m}^{2}$ \\
\hline
\end{tabular}

\subsection{Electrical measurements and calculations}

As mentioned in section 2.1 (Fabrication of the DBD reactor and experimental setup), the main feature of the DBD reactor relevant for the removal of $\mathrm{HCHO}$ is the electric discharge generated in the plasma. It is thus of practical essence to determine the discharge energy released into the system. The following computations were thus performed: 
Degree of removal $\left(\mathbf{C}_{\text {out }} / \mathbf{C}_{\text {in }}\right)$ : This is the ratio of final $\mathrm{HCHO}$ concentration after degradation to initial HCHO concentration. The degree of removal reduces as more pollutant is removed, and hence, the removal efficiency can be obtained as: 1 - (Cout/Cin) [9].

Discharge power (P): It is the average electrical power in watts (W) deposited into and consumed by the ionization reactor chamber. This is needed to calculate the SIE and to characterize the decomposition energy consumption. This paper follows the $\mathrm{Q}-\mathrm{V}$ Lissajous curve method for calculating discharge power, first reported by Manley [16], and recently shown by a host of researchers to give viable results for energy studies in DBD plasma reactor research [17]. It is given as:

$$
\mathrm{P}=\frac{1}{\mathrm{~T}} \int_{0}^{\mathrm{T}} \mathrm{V}_{\mathrm{r}}(\mathrm{t}) \cdot \mathrm{C}_{\mathrm{m}} \frac{\mathrm{dV} \mathrm{V}_{\mathrm{m}}(\mathrm{t})}{\mathrm{dt}} \mathrm{dt}=\frac{1}{\mathrm{~T}} \int \mathrm{V}_{\mathrm{r}} \mathrm{C}_{\mathrm{m}} \mathrm{dV} \mathrm{V}_{\mathrm{m}}=\frac{1}{\mathrm{~T}} \oint \mathrm{V}_{\mathrm{r}} d Q_{\mathrm{m}}
$$

Where $\mathrm{T}$ is the $\mathrm{AC}$ cycle period, $\mathrm{V}_{\mathrm{r}}$ is the high voltage across the reactor, $\mathrm{C}_{\mathrm{m}}$ is the capacitance of the series capacitor also called monitor capacitor. In order to ascertain the discharge power following the Q-V Lissajous curve method, a large capacitance is be chosen relative to the reactor capacitance in order to ensure a very small voltage $\left(\mathrm{V}_{\mathrm{m}}\right)$ across it. $\mathrm{Q}_{\mathrm{m}}$ is the charge on the capacitor. In this experiment, a $4.7 \mu \mathrm{F}$ capacitor is connected in series with the rector as illustrated in figure 1 . The small voltage drop $\left(\mathrm{V}_{\mathrm{m}}\right)$ across the series capacitor is measured with the MASTECH MY-65 digital millimetre, which is then entered into a MATLAB code to compute the charge, $\mathrm{Q}_{\mathrm{m}}$. A graph of $\mathrm{Q}_{\mathrm{m}}$ against $\mathrm{V}_{\mathrm{r}}$ displayed on the oscilloscope is usually a parallelogram, called the Lissajous curve, whose area is the discharge energy realized in the reactor. Thus equation (3) can finally be written as:

$$
P=f \times A
$$

where $\mathrm{f}$ is the high voltage AC frequency in Hertz and $\mathrm{A}$ is the Lissajous area. The electric signals are measured by the digital oscilloscope.

\subsection{Analytical methods}

Firstly, in order to study the effect of electrical discharge on HCHO degradation by the DBD plasma, a high voltage-time $500 \mathrm{MHz}$ Digital Oscilloscope (WaveJet 354A) is connected across the high-voltage supply to obtain the voltage and charge waveforms. This is done by connecting the high-voltage probe (Tektronix, P6015A). The discharge current density is measured with a 
current probe (Tektronix, TCP303), and the root mean square (RMS) value is analyzed. The input and output concentrations of $\mathrm{HCHO}$ is detected by a portable air quality monitor (Aeroqual Series 500) fitted with a formaldehyde sensor head of detection range 0-10ppm, minimum detection limit of $0.01 \mathrm{ppm}$, while the indoor air humidity (20-90\%) is measured by a smart sensor humidity meter. The GCMS processes to investigate possible intermediates and degradation path is as described in Asilevi [9].

The experiment commenced with the initial preparation of a laboratory simulated $\mathrm{HCHO}$ contaminated indoor air by injecting air from a dry air cylinder through water and liquid phase $\mathrm{HCHO}$ at controlled flow rates to generate typical contaminated indoor air with a desired $\mathrm{HCHO}$ concentration, which proceeds and continues to flow into the main DBD reactor for about 5 minutes to ensure a steady condition in the reactor ionization gas gap chamber. At a suitable steady condition, the initial HCHO concentration is noted by the portable air quality monitor (Aeroqual Series 500). The main high voltage supply system across the DBD electrodes was then turned on for plasma ionization discharge generation sustained nearly 10 minutes to attain a fair new $\mathrm{HCHO}$ concentration noted as the output concentration of HCHO. The high voltage supply is then turned off to return reactor to normal state, and the process was repeated several times for different initial concentrations. The entire process followed the description in Asilevi [9].

\section{Results and discussions}

\subsection{Effect of DBD strong ionization on HCHO removal}

As the strength of ionization is the outstanding feature of the DBD reactor for indoor air purification, hence the removal of $\mathrm{HCHO}$, this section analyzed the electrical and ionization characteristics of the DBD reactor using the digital oscilloscope and the effect on removal efficiency. The actual discharge phenomena is filamentary in nature, in which high energy fast moving electrons have collided the air molecules resulting in an electrically energy dense ionized medium comprising active species and energetic electrons, herein non-thermal plasma (NTP). Table 2 summarizes the possible reactions and active species formed in the thin plasma space. In equations 5-8 oxygen molecules undergo ionization and dissociation in the air stream producing a large plasma volume of excited oxygen molecules and other active species. The $\mathrm{O}_{2}^{+} \mathrm{X}^{2} \pi_{\mathrm{g}}$ and $\mathrm{O}_{2}^{+} \mathrm{A}^{4} \pi_{\mathrm{g}}$ are unstable active byproducts proceeding to dissociation and subsequent formation of 
active oxygen particles such as $\mathrm{O}\left({ }^{3} \mathrm{P}\right), \mathrm{O}\left({ }^{2} \mathrm{D}\right)$, and other key oxygen-based ions. Additionally, ionization (equations 9 and 10) and dissociation (equations 11 and 12) of nitrogen gas producing high energy electrons and consequential radicals respectively further enhances plasma strength. $\mathrm{OH}$ and $\mathrm{H}$ radical formation further results from the chemical breakdown of $\mathrm{H}_{2} \mathrm{O}$ represented by equations 13 and 14. Atkinson [18] and Shimizu [19] have shown that $\bullet \mathrm{OH}$ can be formed from the collision of excited state $\mathrm{O}\left({ }^{1} \mathrm{D}\right)$ with $\mathrm{H}_{2} \mathrm{O}$ according to equation 15 .

In the actual situation, the plasma chemical reactions and plasma formation process occurring in the strong ionization discharge reactor involve more complex reactions. Equations 5 - 15 mainly represent the formation of second degree electrons and key active species resulting from discharging of the indoor air. Meanwhile $\bullet \mathrm{OH}, \mathrm{O}_{3}$, and other active species can also be produced by inelastic collision initiated by fast moving electrons with $\mathrm{O}_{2}$ and $\mathrm{H}_{2} \mathrm{O}$ molecules [20, 21]. Oxygen $\left(\mathrm{O}_{2}\right)$ gas and water $\left(\mathrm{H}_{2} \mathrm{O}\right)$ vapor are key deriver species in the air stream influencing the strength of NTP discharge ionization and hence controlling their concentration is relevant for device operation efficiency.

Table 2: Important ionization reactions involving the breakdown of air molecules to form active species in the enhanced ionization plasma

\begin{tabular}{lcc}
\hline Reaction process & $\mathrm{K}$, reaction rate $\left(\mathrm{cm}^{3} / \mathrm{s}\right)$ & Equation numbers \\
\hline $\mathrm{e}^{-}+\mathrm{O}_{2} \rightarrow \mathrm{O}_{2}^{+} \mathrm{X}^{2} \pi_{\mathrm{g}}+2 \mathrm{e}^{-}$ & $4.2 \times 10^{-11}$ \\
$\mathrm{e}^{-}+\mathrm{O}_{2} \rightarrow \mathrm{O}_{2}^{+} \mathrm{A}^{4} \pi_{\mathrm{g}}+2 \mathrm{e}^{-}$ & $9.1 \times 10^{-13}$ \\
$\mathrm{e}^{-}+\mathrm{O}_{2} \rightarrow \mathrm{O}\left({ }^{3} \mathrm{P}\right)+\mathrm{O}\left({ }^{2} \mathrm{D}\right) \mathrm{e}^{-}$ & $4.6 \times 10^{-16}$ \\
$\mathrm{e}^{-}+\mathrm{O}_{2} \rightarrow \mathrm{O}\left({ }^{3} \mathrm{P}\right)+\mathrm{O}\left({ }^{1} \mathrm{D}\right) \mathrm{e}^{-}$ & $3.2 \times 10^{-11}$ \\
$\mathrm{e}^{-}+\mathrm{N}_{2} \rightarrow \mathrm{N}_{2}^{+}\left(\mathrm{X}^{2} \Sigma_{\mathrm{g}}^{+}\right)+2 \mathrm{e}^{-}$ & $1.1 \times 10^{-10}$ \\
$\mathrm{e}^{-}+\mathrm{N}_{2} \rightarrow \mathrm{N}_{2}^{+}\left(\mathrm{B}^{2} \Sigma_{\mathrm{u}}^{+}\right)+\mathrm{e}^{-}$ & $2.7 \times 10^{-11}$ \\
$\mathrm{e}^{-}+\mathrm{N}_{2} \rightarrow \mathrm{N}\left({ }^{4} \mathrm{~S}\right)+\mathrm{N}\left({ }^{4} \mathrm{D}\right)+$ & $2.4 \times 10^{-17}$ \\
$\mathrm{e}^{-}$ & \\
$\mathrm{e}^{-}+\mathrm{N}_{2} \rightarrow \mathrm{N}\left({ }^{4} \mathrm{~S}\right)+\mathrm{N}\left({ }^{2} \mathrm{D}\right)+$ & $2.0 \times 10^{-11}$ \\
$\mathrm{e}^{-}$ & \\
$\mathrm{e}^{-}+\mathrm{H}_{2} \mathrm{O} \rightarrow \mathrm{e}^{-}+\mathrm{H}+\mathrm{OH}$ & $2.6 \times 10^{-12}$ \\
$\mathrm{e}^{-}+\mathrm{H}_{2} \mathrm{O} \rightarrow 2 \mathrm{e}^{-}+\mathrm{H}_{2}^{+}$ & $1.1 \times 10^{-12}$
\end{tabular}




$$
\mathrm{O}\left({ }^{1} \mathrm{D}\right)+\mathrm{H}_{2} \mathrm{O} \rightarrow 2 \mathrm{OH} \quad 2.2 \times 10^{-10}
$$

Displayed on the oscilloscope screen is the characteristic waveform of voltage and current in the $\mathrm{AC}$ powered $\mathrm{DBD}$ captured in figure $3 \mathrm{a}$, with a maximum voltage of $3.0 \mathrm{kV}$. The current waveform shows short spikes indicating micro-discharge activities in the plasma space, hence numerous discharge processes. Furthermore, the current and the voltage waveforms show a varying phase angle between them, in which the current lags behind the voltage. The chargevoltage $(\mathrm{Q}-\mathrm{V})$ Lissajous curve at $2.5 \mathrm{kV}$ shown in Figure $3 \mathrm{~b}$ is a closed parallelogram, whose area according to equation 4 quantifies the discharge power.
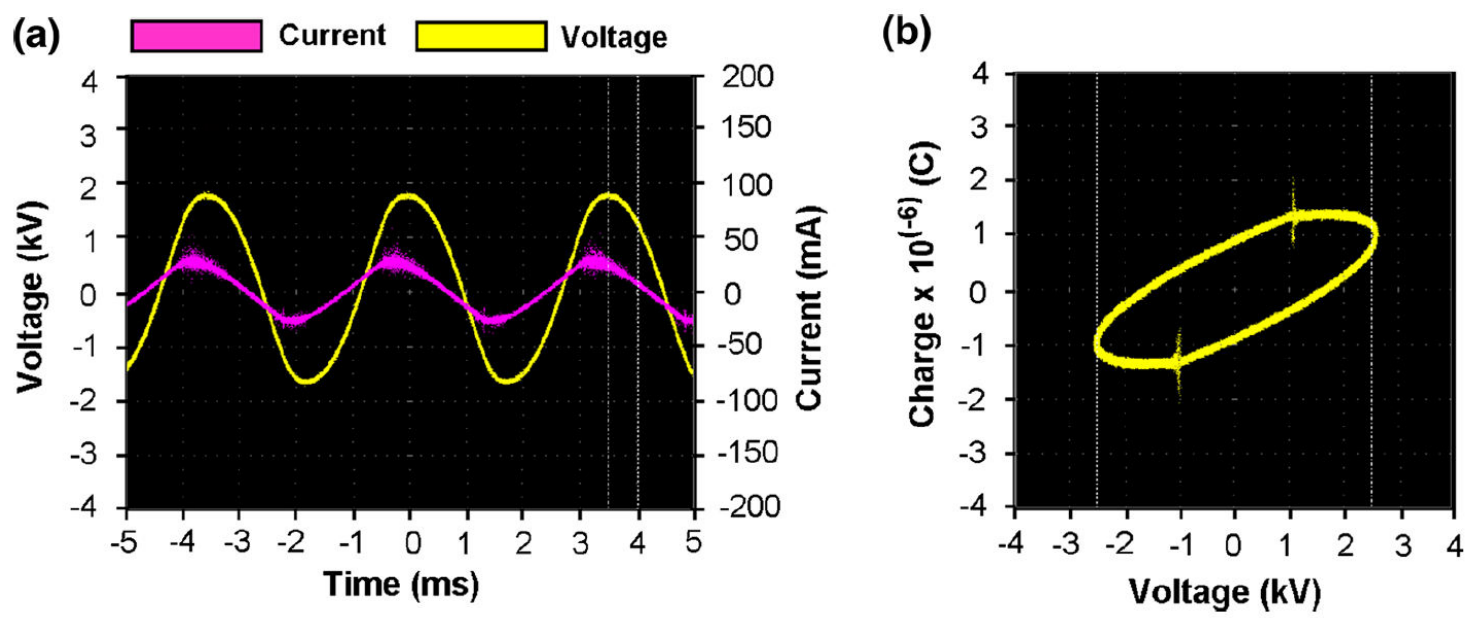

Figure 3: (a) Characteristic waveform of voltage and current in the strong ionization dielectric barrier discharge and (b) the charge-voltage Lissajous curve as shown on the oscilloscope screen

In theory, the lumped-component electrical design of the DBD reactor in figure 1 resembles a lossy capacitor pair representative of the discharge electrodes, the dielectric layer, and the discharge gap, which is comparable to a resistive capacitive circuit. The design is akin to a series resonance in which the reactor terminal voltages could be several times higher than the average voltage. As supply voltage stabilizes and exceeds a specified threshold, the dielectric is electrostatically active with a suitable polarization intensity resulting in the formation a high charge density accumulation around the surface edges thus an enhanced local inhomogeneous electric field. Based on the typical voltage and current wave distributions, the electric field is 
computed and analyzed by $\mathrm{E}=[3 \varepsilon /(\varepsilon+2)] \mathrm{E}_{\mathrm{o}} \cos \theta$ [9]. Here, $\mathrm{E}$, $\varepsilon$, and $\theta$ are the localized electric field intensity, permittivity, and current - voltage phase angle.

From this analysis, it is apparent that the electric field $\mathrm{E}$ relates proportionally to a threshold $E_{o}$, such that, a larger dielectric constant will enhance $E$ to reach three times of $E_{o}$ when $\theta=0$. Thus, increasing the DBD average terminal voltage will increase the electric field intensity, which will result in large discharge power. This electrical effect is of key practical relevance in the degradation of $\mathrm{HCHO}$, as an enormous quantity of high energy electrons are produced by the increased discharge power, and hence increased plasma ionization density which will increase the chance of numerous collisions with $\mathrm{HCHO}$ molecules thereby increasing the removal efficiency. The experimental results confirming the theory and thus agreeing with the observation of other studies [17] is shown in figure 4.

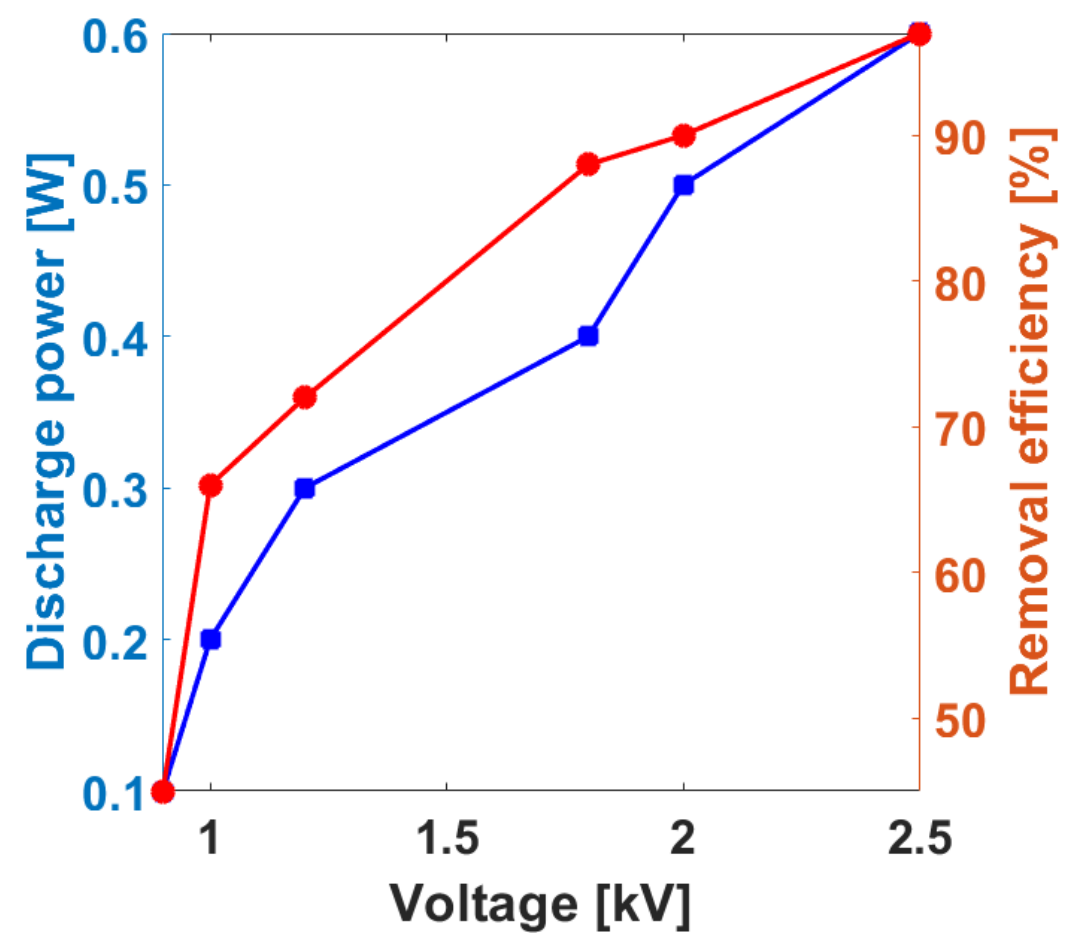

Figure 4: Effect of high voltage supply on ionization discharge power and removal efficiency at ambient conditions

In addition, figure 4 shows the effect of increasing discharge power by the strong ionization DBD on removal efficiency of HCHO. Formaldehyde vapor was diluted with air stream to input initial concentration of $1.0 \mathrm{ppm}$. From the experimental data, the removal efficiency of $\mathrm{HCHO}$ at 
$0.1 \mathrm{~W}$ was $45.4 \%$ which increased to $97 \%$ at $0.6 \mathrm{~W}$ under ambient conditions. Apparently, increased input voltage supplied more plasma discharge power which consequentially increased the removal efficiency of $\mathrm{HCHO}$ by the DBD reactor, and thus the discharge power shows positive correlation relation with removal efficiency. As mentioned, increasing the discharge power causes enhanced NTP ionization which makes available degradation active species [19]. It is worth mentioning that, in a previous study to remove $\mathrm{HCHO}$ by a similar strong ionization DBD reactor, Asilevi [9] reported that increasing discharge power caused ozone generation which eventually reduced when $\mathrm{HCHO}$ initial concentration increased, suggesting $\mathrm{HCHO}$ consumption of $\mathrm{O}_{3}$ during the degradation process. However, removal efficiency seem to be saturated in the neighborhood of $97 \%$ with further increase in discharge power beyond $0.6 \mathrm{~W}$.

\subsection{Effect of Initial concentration $\left(C_{i n}\right)$}

For application purpose, the effect of adjusting inlet concentration is relevant to achieve optimum removal. This section describes experimental results on the impact of initial HCHO concentration in the air stream on removal efficiency at different discharge power $(0.1 \mathrm{~W}, 0.3 \mathrm{~W}$, and $0.8 \mathrm{~W}$ ) shown in figure 5 . The inlet concentration was adjusted between 0.1 and $0.6 \mathrm{ppm}$ under total air flow rate of $0.5 \mathrm{~m}^{3} / \mathrm{h}$ at ambient conditions. It is apparent that the removal efficiency shows a strong negative correlation with the initial concentration of formaldehyde, such that removal efficiency decreased from $70.9-25 \%$ at $0.1 \mathrm{~W}, 88-30 \%$ at $0.3 \mathrm{~W}$, and $98-$ $50.5 \%$ at $0.8 \mathrm{~W}$. 


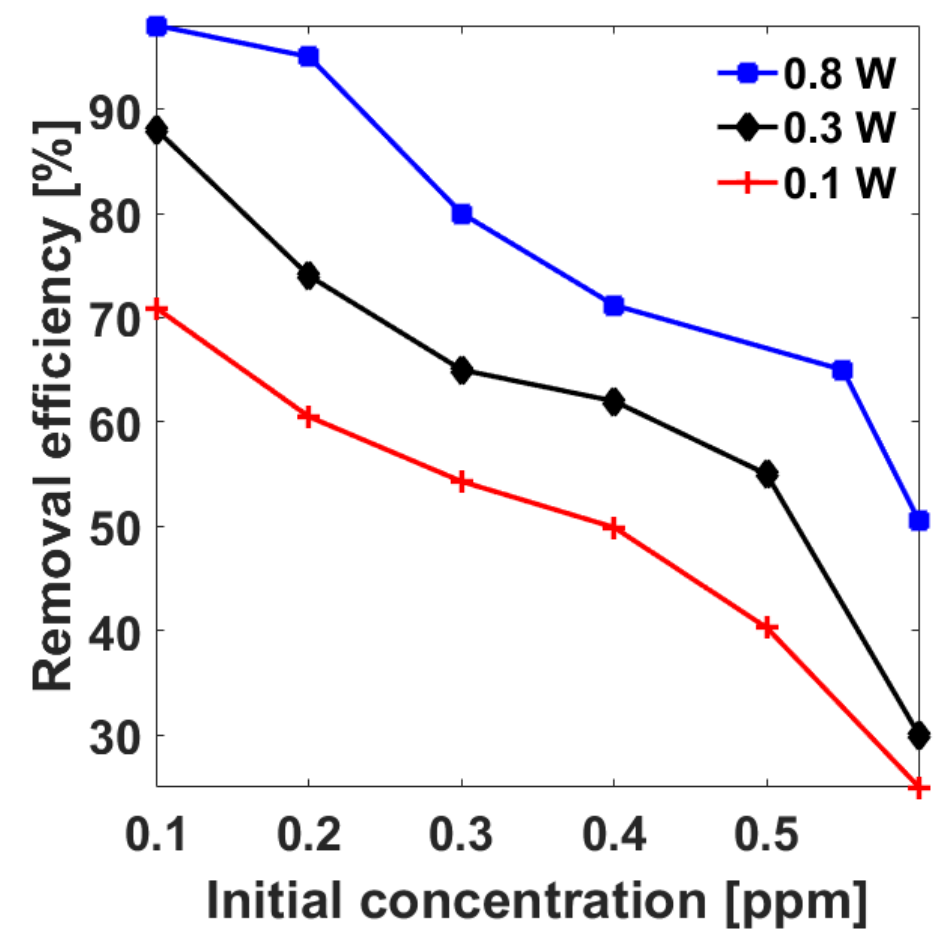

Figure 5: Effect of initial HCHO concentration on removal efficiency at different discharge power

Therefore, at ambient air conditions and reasonable flow rate, removal efficiency decreases with increasing initial $\mathrm{HCHO}$ concentration. The observation is attributed to the fact that increased inlet concentration results in increased $\mathrm{HCHO}$ molecule population, which reduces the chance of inelastic collisions for $\mathrm{HCHO}$-electron and $\mathrm{HCHO}$-active species impact owing to limited contact with individual $\mathrm{HCHO}$ molecules, thus tampering effective removal efficiency. Such effect was similarly reported by Hongxiang [22] and Asilevi [9].

\subsection{Effect of air flow rate}

Since the strong ionization discharge reactor volume remains constant, the residence time expended by a specified volume of air stream in the reactor chamber is inversely related to the gas flow rate. Figure 6 shows that at any given discharge power, reducing flow rate of the air stream from $2-0.2 \mathrm{~m}^{3} / \mathrm{h}$ increases HCHO removal efficiency over increasing operation time. For example, during thirty (30) minutes operations time, the removal efficiency reached 68\%, 88\%, and $95 \%$ at $2 \mathrm{~m}^{3} / \mathrm{h}, 1.5 \mathrm{~m}^{3} / \mathrm{h}$, and $0.2 \mathrm{~m}^{3} / \mathrm{h}$ flow rates respectively. This agrees with the observation of Hongxiang [22]. 


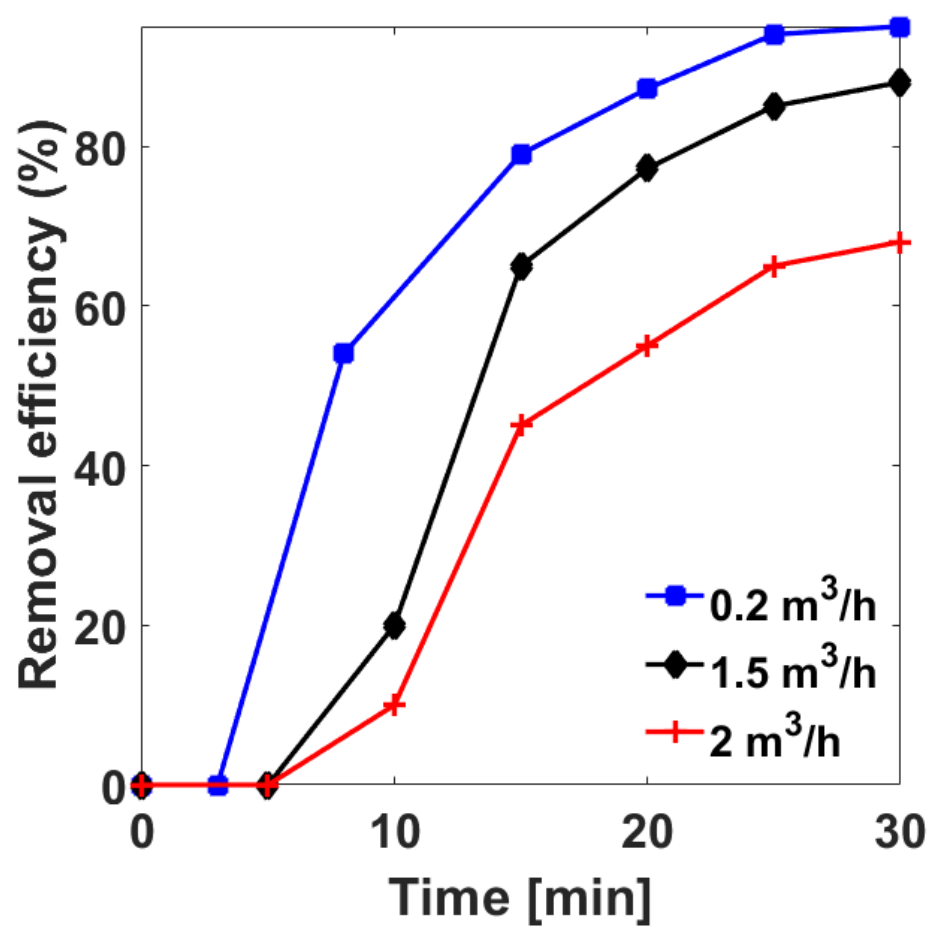

Figure 6: Effect of air stream flow rate on removal efficiency at different discharge power

In practice, as the air flow rate increases, the instantaneous reacting air volume decreases and the reaction time shortens. Although the chances of inelastic collision of gas molecules with active species and energetic electrons may increase due to high discharge power, the shortened reaction time makes more gas molecules pass directly through the reactor without any significant interaction with active species and electrons. The magnitude of the air stream residence time required to efficiently remove $\mathrm{HCHO}$ suggests that the prospect of tuning the reactor in order to treat large indoor air space is quite promising.

\subsection{Effect of Relative humidity (RH)}

The $\cdot \mathrm{OH}$ radical which results from the breakdown of water vapor $\left(\mathrm{H}_{2} \mathrm{O}\right)$ due to inelastic collisions with high energy electrons and other active particles such as $\mathrm{O}\left({ }^{1} \mathrm{D}\right)$ according to equations 13 - 15 plays a key role in bacterial decontamination and removal of VOCs in water and flue gases, because of their tendency toward strong oxidation in many physicochemical processes [23]. Studies by Shimizu [19] and Storch [24] reported that the destruction of HCHO by NTP in flue gas results predominantly from chemical attack by $\bullet \mathrm{OH}$ and $\bullet \mathrm{O}$ radicals. Thus this section studied the effect of water vapor on the removal efficiency of HCHO by the strong 
ionization DBD. Figure 7 shows that as the discharge power increased, the removal efficiency increased with increasing relative humidity (percentage of $\mathrm{H}_{2} \mathrm{O}$ present in air stream); for example, increasing the RH from $20-70 \%$ increased the removal efficiency from $50.5-96 \%$ at $0.1 \mathrm{~W}, 55.8-96 \%$ at $0.3 \mathrm{~W}$, and $60.5-97 \%$ at $0.8 \mathrm{~W}$ all under atmospheric pressure and room temperature. The results show that, discharge power and RH concurrently enhanced removal efficiency of $\mathrm{HCHO}$ by the DBD under standard conditions.

The physiochemical effect of water vapor on the formation of plasma air stream is well documented by Shimizu [19], Storch [24], and Asilevi [9]. In analyzing the root mean square (RMS) current as a function of electron density in similar dielectric barrier discharge plasma system using an oscilloscope, [9] realized that increasing RH between 20 and $60 \%$ had a reducing effect on RMS current at all supply voltages, and deduced that electrons produced by the discharge process are consumed to break down $\mathrm{H}_{2} \mathrm{O}$ vapor molecules to generate $\cdot \mathrm{OH}$ radicals according to equation 13 . This in turn reduces the amount of discharge electrons, thus current density. Consequentially, more $\cdot \mathrm{OH}$ radicals are formed and more $\mathrm{HCHO}$ molecules are destroyed increasing reactor efficiency. However, previous experiments show that, a normalization of slight deviation occurs beyond some RH limit. Chang [25] attribute this to the fact that the electronegativity of water vapor tends to raise the minimum electric field $(E N)_{0}$, where $\mathrm{E}$ is electric field strength and $\mathrm{N}$ the total air molecule number density, required to generate the plasma. According to equation 14, this situation multiplies electrons. This further confirms that the entire micro-discharge process is a complex one. This observation is relevant for the manufacture of DBD devises for indoor air purification in the built environment, since RH changes seasonally; an intelligent RH sensor and water vapor supply components can be fixed to regulate the air stream $\mathrm{RH}$ for optimum air purification. 


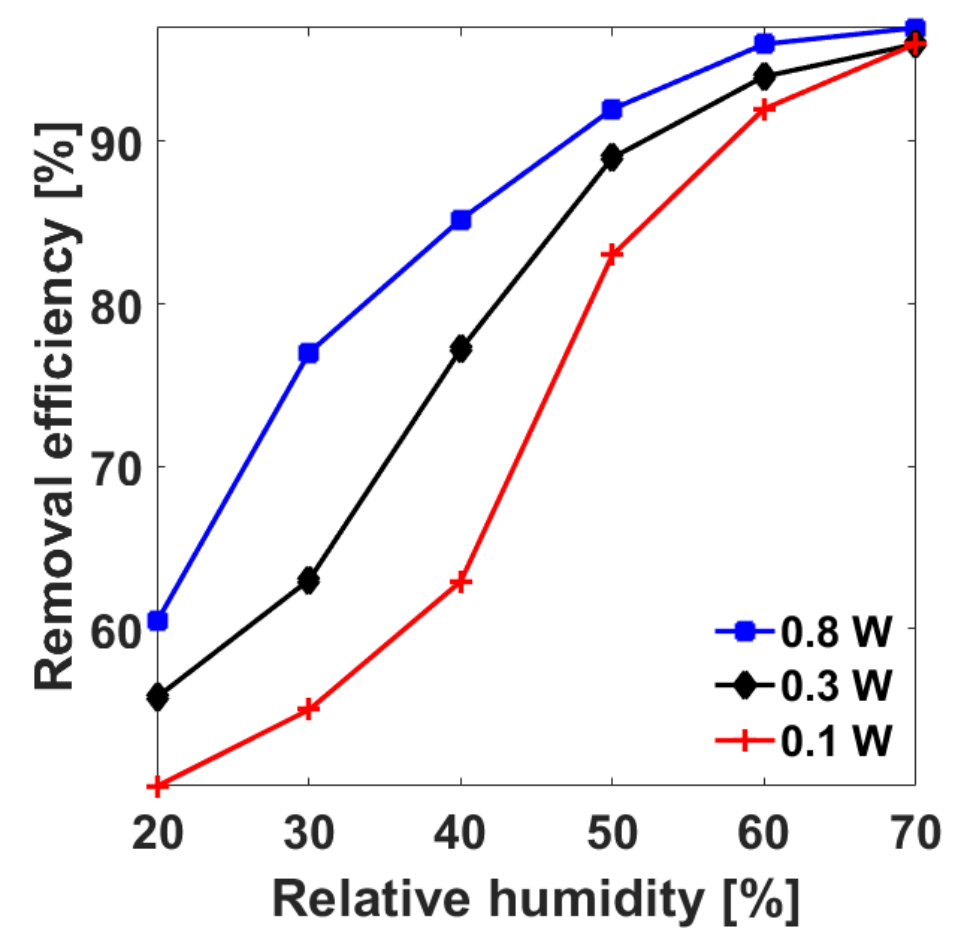

Figure 7: Effect of indoor air humidity on removal efficiency at different discharge power under atmospheric pressure and room temperature

\subsection{HCHO degradation intermediates and chemical pathway}

The plasma effect on the degradation of formaldehyde was previously studied by Asilevi [9], Shimizu [19], and Storch [24] and reported theoretical and experimental insights which emphasis from Gas chromatography-mass spectrometry (GCMS) and Fourier-transform infrared spectroscopy (FTIR) results that $\mathrm{HCHO}$ degradation starts primarily by equations 16 and 17 involving $\bullet \mathrm{HCO}$ and $\bullet \mathrm{OH}$ and $\bullet \mathrm{HCO}$ and $\bullet \mathrm{O}$ inelastic collisions. In addition, direct $\mathrm{HCHO}$ conversion to $\mathrm{H}_{2} \mathrm{O}$ and $\mathrm{O}_{2}$ by electron collision also occurs under similar conditions. Further degradation of $\bullet \mathrm{HCO}$ occurs through collisions with high speed electrons to form relatively small molecules (including $\bullet \mathrm{CH}_{3}, \cdot \mathrm{CH}_{3} \mathrm{CH}_{2}, \cdot \mathrm{CH}_{3} \mathrm{CH}_{2} \mathrm{O}, \cdot \mathrm{CH}_{2} \mathrm{O}, \bullet \mathrm{OHCO}, \cdot \mathrm{CH}_{3} \mathrm{OH}$ ) and other organic particles. The reaction equations involved in the plasma processing degradation of $\mathrm{HCHO}$ are summarized in table 3 [19].

Table 3: Intermediate chemical reactions in the degradation of $\mathrm{HCHO}$ leading to the formation of $\mathrm{CO}_{2}$ and $\mathrm{H}_{2} \mathrm{O}$ 


\begin{tabular}{llc}
\hline Reaction process & $\mathrm{K}$, reaction rate $\left(\mathrm{cm}^{3} / \mathrm{s}\right)$ & Equation numbers \\
\hline $\mathrm{HCHO}+\mathrm{O} \rightarrow \mathrm{HCO}+\mathrm{OH}$ & $2.99 \times 10^{-11}$ & \\
$\mathrm{HCHO}+\mathrm{OH} \rightarrow \mathrm{HCO}+\mathrm{H}_{2} \mathrm{O}$ & $1.6 \times 10^{-11}$ & \\
$\mathrm{HCHO}+\mathrm{OH} \rightarrow \mathrm{H}+\mathrm{HCOOH}$ & $2 \times 10^{-13}$ & $3.64 \times 10^{-16}$ \\
$\mathrm{HCHO}+\mathrm{H} \rightarrow \mathrm{HCO}+\mathrm{H}_{2}$ & $4.80 \times 10^{-13}$ & \\
$\mathrm{HCOOH}+\mathrm{OH} \rightarrow \mathrm{H}_{2} \mathrm{O}+\mathrm{CO}_{2}+\mathrm{H}$ & $8.50 \times 10^{-3}$
\end{tabular}

Due to the highly active state in the plasma system during the degradation, the intermediate byproducts retain high instability. More also, the strength of oxidation of $\bullet \mathrm{OH}$ and $\bullet \mathrm{O}$ radicals generated in the strong ionization discharge plasma have strong oxidation potentials which further oxidize these intermediates byproducts. A serial plasma chemical reactions further lead to the breakdown of the small intermediate molecules and the direct electron-degraded $\mathrm{HCHO}$ to form $\mathrm{CO}_{2}$ and $\mathrm{H}_{2} \mathrm{O}$. A suggested degradation chemical path is shown in figure 8 . 


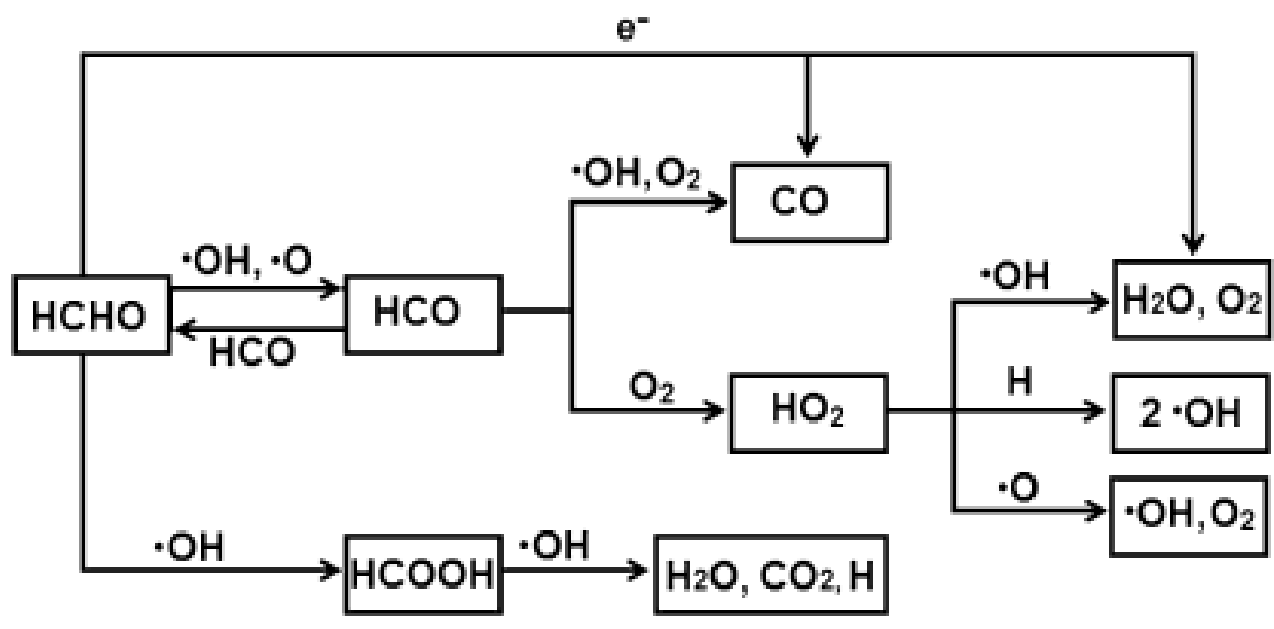

Figure 8: Suggested plasma processing degradation chemical path for HCHO removal in the contaminated indoor air stream

\subsection{Optimization of the Processing Conditions}

In order to ascertain an optimized condition for low-concentration $\mathrm{HCHO}$ removal from indoor air using the strong ionization DBD devise, several experiments under different processing conditions were performed, and sample results were selected as input data for a linear statistical regression analysis to determine which process parameters showed the strongest impact on the removal efficiency following a similar approach by Hongxiang [22]. Table 4 shows the results for the statistical regression equation analysis of the effect of different processing parameters on the removal efficiency.

As seen, $\mathrm{HCHO}$ removal efficiency ( $\eta$ ) showed a strong linear correlation dependence on all the experimented processing parameters i.e. discharge power $(\mathrm{P})$, initial concentration $\left(\mathrm{C}_{\text {in }}\right)$, flow rate $(F)$, and relative humidity $(\mathrm{RH})$ of $\mathrm{R}^{2}=0.93,0.94,0.99$, and 0.96 respectively. However, the dependence equations with discharge power $(\mathrm{P})$ and relative humidity $(\mathrm{RH})$ have positive slopes of 99.4 and 0.8 respectively, while initial concentration $\left(\mathrm{C}_{\mathrm{in}}\right)$ and flow rate $(\mathrm{F})$ have negative slopes of -87.6 and -43.7 respectively. This is expected since as discussed the removal efficiency increases with increasing discharge power and relative humidity, but decreases with increasing initial concentration and flow rate. Meanwhile, the $\eta-F$ regression gave the strongest correlation 
coefficient $\left(\mathrm{R}^{2}=0.99\right)$ indicating that air flow rate in the most relevant parameter to achieve optimum degradation.

Table 4: Statistical effect of different processing conditions the removal efficiency

\begin{tabular}{|c|c|c|c|c|c|c|c|}
\hline $\begin{array}{c}\text { Discharge } \\
\text { power } \\
\text { (W) }\end{array}$ & $\begin{array}{c}\text { Removal } \\
\text { efficiency, } \\
\text { n (\%) }\end{array}$ & $\begin{array}{c}\text { Initial } \\
\text { con., } C_{\text {in }} \\
\text { (ppm) }\end{array}$ & $\begin{array}{c}\text { Removal } \\
\text { efficiency, } \\
\text { n (\%) }\end{array}$ & $\begin{array}{c}\text { Flow } \\
\text { rate } \\
\left(\mathbf{m}^{\mathbf{3}} / \mathbf{h}\right)\end{array}$ & $\begin{array}{c}\text { Removal } \\
\text { efficiency, } \\
\text { n (\%) }\end{array}$ & $\begin{array}{c}\text { Relative } \\
\text { humidit } \\
\text { y }(\%)\end{array}$ & $\begin{array}{c}\text { Removal } \\
\text { efficiency } \\
\eta(\%)\end{array}$ \\
\hline 0.1 & 45 & 0.1 & 85.6 & 1.5 & 20.0 & 20 & 55.5 \\
\hline 0.2 & 66 & 0.2 & 76.5 & 2.0 & 28.0 & 30 & 65.0 \\
\hline 0.3 & 72 & 0.3 & 66.4 & 0.8 & 63.0 & 40 & 75.1 \\
\hline 0.4 & 88 & 0.4 & 61.0 & 0.6 & 73.1 & 50 & 88.0 \\
\hline 0.5 & 90 & 0.55 & 53.4 & 0.4 & 81.3 & 60 & 94.0 \\
\hline 0.6 & 97 & 0.6 & 35.2 & 0.2 & 83.7 & 70 & 96.3 \\
\hline \multicolumn{2}{|c|}{$y=99.4 x+41.53$} & \multicolumn{2}{|c|}{$y=-87.6 x+94.42$} & \multicolumn{2}{|c|}{$y=-43.7 x+96.6$} & \multicolumn{2}{|c|}{$y=0.8 x+39.92$} \\
\hline \multicolumn{2}{|c|}{$\mathrm{R}^{2}=0.93$} & \multicolumn{2}{|c|}{$\mathrm{R}^{2}=0.94$} & \multicolumn{2}{|c|}{$\mathrm{R}^{2}=0.99$} & \multicolumn{2}{|c|}{$\mathrm{R}^{2}=0.96$} \\
\hline
\end{tabular}

\section{Conclusion}

In this paper, authors developed a laboratory scale dielectric barrier discharge (DBD) reactor which generates an enhanced atmospheric non-thermal plasma (NTP) to study the removal of low-concentration formaldehyde (HCHO), a typical indoor air VOC in the built environment associated with cancer and leukemia at unsafe levels $(>0.1 \mathrm{ppm})$, under different processing conditions. A strong ionization NTP was generated between DBD electrodes by a pulse power zero-voltage switching flyback transformer (ZVS-FBT), which causes ionization of air molecules leading to active species formation to convert $\mathrm{HCHO}$ into carbon dioxide $\left(\mathrm{CO}_{2}\right)$ and water vapor $\left(\mathrm{H}_{2} \mathrm{O}\right)$. Under different processing conditions i.e. discharge power $(\mathrm{P})$, initial concentration $\left(\mathrm{C}_{\mathrm{in}}\right)$, flow rate $(\mathrm{F})$, and relative humidity $(\mathrm{RH})$, the removal efficiency was determined. The results show that, (i) the DBD device efficient removed low-concentration formaldehyde by $99 \%$ without the use of catalyst with no secondary pollution, (ii) the removal efficiency can be increased by increasing the exerted voltage hence discharge power within the range that the reactor can endure (iii) the correlation coefficient $\left(\mathrm{R}^{2}\right)$ of removal efficiency dependence on the processing parameters follow the order $\mathrm{F}=0.99>\mathrm{RH}=0.96,>\mathrm{C}_{\mathrm{in}}=0.94>\mathrm{P}=$ 0.93, iv) in the degradation process the flow rate showed the strongest impact on removal efficiency though negative, indicating a decrease in removal efficiency with increasing fume flow the efficiency reduces, and v) the processing optimization statistical results indicate that 
when the discharge power $(\mathrm{P})$, initial concentration $\left(\mathrm{C}_{\mathrm{in}}\right)$, flow rate $(\mathrm{F})$, and relative humidity (RH) were $0.6 \mathrm{~W}, 0.1 \mathrm{ppm}, 0.2 \mathrm{~m}^{3} / \mathrm{h}$, and $60-70 \%$ respectively, the efficiency was $98.45 \%$. The experimental results are relevant in the manufacture of DBD technology for improving Indoor Air Quality (IAQ) by removing Volatile Organic Compounds.

\section{References}

1. Kang, D. S. et al. Formaldehyde exposure and leukemia risk: a comprehensive review and network-based toxicogenomic approach. Genes Environ.. 43, 1-10 (2021).

2. Sarkhosh, M. et al. Indoor Air Quality associations with sick building syndrome: an application of decision tree technology. Build Environ. 188, 107446 (2021).

3. Sun, Y. et al. Indoor air quality, ventilation and their associations with sick building syndrome in Chinese homes. Energy Build. 197, 112-119 (2019).

4. Tran, V. V., Park, D., \& Lee, Y. C. Indoor air pollution, related human diseases, and recent trends in the control and improvement of indoor air quality. Int. J. Environ. Res. Public Health. 17, 2927 (2020).

5. Shimizu, K., Kristof, J., \& Blajan, M. G. Applications of Dielectric Barrier Discharge Microplasma in Atmospheric Pressure Plasma-from Diagnostics to Applications (ed. Nikiforov A. \& Chen Z.) 71-93 (IntechOpen, 2019).

6. Jarraya I., Fourmentin S., Benzina M., \& Bouaziz S.. VOC adsorption on raw and modified clay materials. Chem. Geol. 275, 1-8 (2010).

7. Mustafa, M. F. et al. Application of non-thermal plasma technology on fugitive methane destruction: Configuration and optimization of double dielectric barrier discharge reactor. $J$. Clean. Prod. 174, 670-677 (2018).

8. Paradisi, C., Marotta, E., \& Locke, B. R. Papers by Selected Lecturers at the 11th International Symposium on Non-thermal/Thermal Plasma Pollution Control Technology \& Sustainable Energy (ISNTPT 11). Plasma Chem. Plasma Process. 39, 519-522 (2019).

9. Asilevi, P. J. et al. Decomposition of formaldehyde in strong ionization non-thermal plasma at atmospheric pressure. Int. J. Environ. Sci. Technol, 17, 765-776 (2020). 
10. Timmermann, E. et al. Indoor air purification by dielectric barrier discharge combined with ionic wind: physical and microbiological investigations. J. Phys. D: Appl. Phys. 51, 164003 (2018).

11. Zadi, et al. Indoor air treatment of refrigerated food chambers with synergetic association between cold plasma and photocatalysis: Process performance and photocatalytic poisoning. Chem. Eng. J. 382, 122951 (2020).

12. Yuan, J. et al. Experimental Study on the Removal of Formaldehyde by Plasma-Catalyst. In IOP Conf. Ser.: Earth Environ. Sci. 435, 012004 (2020).

13. Zhang, H. et al. High efficient styrene mineralization through novel NiO-TiO2-Al2O3 packed pre-treatment/treatment/post-treatment dielectric barrier discharge plasma. Chem. Eng. J. 343, 759-769 (2018).

14. Napartovich, A. P.. Overview of atmospheric pressure discharges producing nonthermal plasma. Plasma Polym. 6, 1-14 (2001).

15. Fridman, A., Chirokov, A., \& Gutsol, A. Non-thermal atmospheric pressure discharges. $J$. Phys. D: Appl. Phys. 38, R1 (2005).

16. Manley, T. C. The electric characteristics of the ozonator discharge. Trans. Electrochem. Soc. 84, 83 (1943).

17. Kriegseis, J., Möller, B., Grundmann, S., \& Tropea, C. Capacitance and power consumption quantification of dielectric barrier discharge (DBD) plasma actuators. J. Electrost. 69, 302-312 (2011).

18. Atkinson, R. et al. Evaluated kinetic and photochemical data for atmospheric chemistry: Volume II-gas phase reactions of organic species. Atmos. Chem. Phys. 6, 3625-4055 (2006).

19. Shimizu, K., Kuwabara, T., \& Blajan, M. Study on decomposition of indoor air contaminants by pulsed atmospheric microplasma. J. Sens. 12, 14525-14536 (2012).

20. Bo, Z. et al. Effects of oxygen and water vapor on volatile organic compounds decomposition using gliding arc gas discharge. Plasma Chem. Plasma Process. 27, 546-558 2007. 
21. Feng, L., Zhang, B., Zhi, F., \& Wenchun, W. Generation of reactive atomic species of positive pulsed corona discharges in wetted atmospheric flows of nitrogen and oxygen. Plasma Sci. Technol. 19, 064008 (2017).

22. Hongxiang, O. et al. Study on formaldehyde degradation using strong ionization discharge in 2010 international conference on mechanic automation and control engineering. 2094-2097. (IEEE, 2010).

23. Liu, F., Wang, W., Wang, S., Zheng, W., \& Wang, Y. Diagnosis of OH radical by optical emission spectroscopy in a wire-plate bi-directional pulsed corona discharge. J. Electrost. $\mathbf{6 5}$, 445-451 (2007).

24. Storch, D. G., \& Kushner, M. J.. Destruction mechanisms for formaldehyde in atmospheric pressure low temperature plasmas. J. Appl. Phys. 73, 51-55 (1993).

25. Chang, M. B., \& Lee, C. C.. Destruction of formaldehyde with dielectric barrier discharge plasmas. Environ. Sci. Technol. 29, 181-186 (1995).

\section{Acknowledgements}

We appreciate the support by the Regional Water and Environmental Sanitation Centre Kumasi (RWESCK), of the Kwame Nkrumah University of Science and Technology (KNUST)

\section{Author contributions}

P. J. A., P. B., and Y. A. S. N designed the research, performed the computations, and wrote the manuscript text and S. O. K. and B. F. B. supervised the findings of this work. All authors discussed the results and contributed to the final manuscript

\section{Competing interests}

The authors declare no competing interests. 